\title{
8. Pluralism and Medical Science
}

Cultural monism and religious fundamentalism are nowadays often without much thought contrasted with cultural and religious pluralism. But let us pause for a moment and ask what is and can be meant by pluralism. Are there different kinds of pluralism? If so, are all of them positive? Might it not be the case that pluralism can be desirable within certain areas but undesirable in others? Is pluralism within society at large one thing, and pluralism within the sciences another? In this chapter we will reflect on these topics.

\subsection{What is pluralism?}

Primarily, 'pluralism' means multiplicity. Where there is pluralism there is a multiplicity of something. But the word 'pluralism' has also received a secondary meaning: where there is pluralism there should be freedom for each individual to choose what part of the multiplicity he wants to have or to belong to. That is, pluralism in a certain respect should be kept distinct from a corresponding multiplicity that is based only on power balance. Today, most countries are pluralistic in several respects; they contain many different cultures, religions, and political parties - between which the citizens are free to choose.

Democracy is political pluralism, and freedom of religion is religious pluralism. In a democratic society, different political parties identify each other as political parties, and the citizens have the right to vote for and be members of the party they prefer. In a totalitarian society, people opposing the party or ideology in power are not identified as being political opponents, but as opponents that represent pure evil, a betrayal of absolute values, or as being simply mentally sick. Therefore, they are not allowed to speak and organize freely and to appear as political opponents. Similarly, in a religiously fundamentalist society, other religions are not really regarded as religions. They are merely conceived as heresies or paganisms. According to the fundamentalist, there is only one religion worth the epithet. Therefore, to him, the very notion of 'religions freedom' is at bottom nonsensical. 
What is involved in a shift from a non-pluralistic attitude to a pluralistic one can be exemplified by the case of language. Our pluralistic attitude towards language is so well entrenched that we do not even think of it as pluralistic. No one thinks that his language is the one and only true language and fights other languages just because they deviate from the true language. But this has seemingly not always been the case. The Greek word for foreigner, 'barbarian', originally meant a person who babbles, i.e., a person who talks or makes noises but does not say anything that is meaningful. Probably, when the Greeks first encountered foreign cultures, they perceived these as lacking a language in the way we perceive even pet animals as lacking a real language. This is not strange; this is the way a very foreign language appears when it is first met with. Since nowadays we take it for granted that all human cultures have a proper language, we reflectively know that, in fact, what appears to us as mere babbling is much more than that, but once this could not have been equally obvious.

Something crucial happens when people begin to perceive what has so far appeared as babbling as meaningful language acts. The distance from the 'barbarians' diminishes; the latter are no longer as dissimilar as was first thought. Correspondingly, there is a difference between regarding our own political ideology or religion (atheism included) as the only ideology or religion worth the label 'political view' and 'religious view', respectively, and as regarding them as one among several possibilities. It is one thing to regard a whole population as consisting of heretics, and quite another to regard it as a people with another religion.

A shift from a totalitarian or fundamentalist perspective to a pluralistic one can, but need not, mean that all the old conflicts disappear. But it means at least that the conflicts are given a somewhat more peaceful form. When those who were formerly described as barbarians, betrayers, heathens, or representatives of evil become described as political opponents or members of another religion, they are naturally treated less ruthlessly. Pluralism always implies some tolerance.

Freedom of religion and democracy are the two grand pluralisms, but even other pluralisms have grown stronger. Nowadays, we are allowed to dress very much the way we want, and we are allowed to live in many different kinds of family-like relationships. Even the old opposition between (presumed normal) heterosexuality and (and presumed perverse) 
homosexuality has very much become reduced to a distinction between two mere forms of sexuality, heterosexuality and homosexuality.

\subsection{Pluralism in the sciences}

During the last decades of the twentieth century, Western universities witnessed quite a change towards pluralism with respect to scientific theories and theorizing. It was most pronounced in the social sciences and the humanities. For instance, in psychology there are nowadays several rival theories such as cognitive psychology, behaviorism, humanistic psychology, various versions of psychoanalytic psychology, and so forth. In literary studies we find different research traditions such as hermeneutics, structuralism, semiotics and post-structuralism.

Within the medical sciences, pluralism is most conspicuous in psychiatry and in the acceptance of some alternative medicine. In psychiatry today, many types of psychotherapies and their underlying theories are used, but as late as during the 1960s they were in many countries classified as unscientific and being quackery. For a long period, electro-stimulating (ECT) and pharmacological treatment were the only psychiatric therapies sanctioned by official science.

In this subchapter we intend to remark only on pluralism within the scientific communities themselves. In most modern societies, scientific communities are allowed to be quite autonomous and self-contained, but they are not absolutely autonomous; and there is really much to discuss about how to obtain an optimal relationship between society and science, but we will not enter this discussion. We will only mention the two most obvious links: (a) the curriculum for primary schools and (b) laws and regulations for scientifically based professions.

(a) In modern societies, science is the public knowledge authority, but it is not allowed all by itself to decide what the primary schools shall teach as being simply facts, i.e., scientific facts. Here, political authorities have the last word, even though they normally respect what is the majority view within the scientific community. But not always, as is shown by the fight around creationism in the US; in several states there has been political quarrel about whether Big Bang cosmology and evolutionary biology shall be taught as facts, or whether they and Biblical creationism should be presented as merely two competing explanations. 
(b) The discussion around alternative medicine and therapies such as chiropractics, acupuncture, reflexiology, homeopathy and magnetic therapy illustrates that pluralism sometimes need to be pluralism with explicitly stated limits. The medical sciences are related to the medical professions, which, in turn, are related to the encompassing society and its laws. Many countries have 'quackery laws', which means that in these countries there is not only an informal consensus among the medical scientists where to draw the line between medical science and non-science, but that there are also formal laws that state where parts of this line are to be found. The quack does not represent a competing scientific theory or paradigm; he represents a lack of science. Of course, fallibilism implies that one can be mistaken even in judgments about quackery.

Pluralism in university science has two areas: teaching and research. With respect to rival theories there is both the question 'which of these rivals should be taught as being truthlike, possibly truthlike, and completely obsolete, respectively?' and the question 'which of these rival hypotheses should be given funding for research?' We will mostly, however, make our remarks without bringing in the distinction between teaching and research; that is, many of our remarks are quite abstract. First, in order to understand the way pluralism functions in science, one has to realize that there are two different forms of pluralism:

- acceptive pluralism, i.e., pluralism without conflict and competition

- competitive pluralism, i.e., pluralism with conflict and competition.

Let us take a brief look at pluralism in dressing habits, pluralism in politics, and ecumenical movements. Pluralism in dressing often means 'you can dress the way you want, and I will dress the way I want'; and then there is no debate about who wears the proper kind of clothes. All kinds are accepted; this is acceptive pluralism, and it is not the way a democracy works. Political pluralism is not meant to take away debates from the political arena. On the contrary, it is meant to encourage competition and discussions between the different political parties. Independently of whether one wants to say that democratic political parties compete about who is best suited to create a good society for all, or that they compete about who should be allowed to favor their pet social strata in society, it is 
clear that democracy means competitive pluralism. Ecumenical movements, on the other hand, attempt to get rid of conflict and competition; both the Christian ecumenical movement and macroecumenical movements for all religions aim at turning the respective competitive religious pluralisms into acceptive pluralisms.

Now, what about the scientific community? Given its modern relative independence from the rest of society, should it be pluralistic? Trivially, it should contain and accept the multiplicity that comes with the division of labor between the different scientific disciplines. That is: 'you can work the way you want in your field, and I will work the way I want in mine'. There is no need to discuss this acceptive pluralism; let it only be noted that even here there may be competition about money. In such disputes, each discipline has to argue that it is more important to support its specific kind of knowledge than the others. In what follows we will be concerned only with the question of pluralism within one single discipline or specific domain of research.

Pluralism by definition implies a lack of consensus - against the background consensus of the pluralistic framework itself. But is it acceptable for a mature scientific discipline to lack consensus? Many academics have taken the picture of science that Kuhn paints in The Structure of Scientific Revolutions (Chapter 2) as implying, that a discipline that has a long-lasting pluralism cannot be a mature scientific discipline. We think that this is a false conclusion. It is not warranted by the history of science, and it seems not to take into account the fact that basic empirical theories as empirically underdetermined (Chapter 3). Therefore, our questions will be:

- should pluralism in a specific scientific domain be acceptive or competitive pluralism?

- if competitive, does it make more than metaphorical sense to appoint winners and losers in scientific contests?

From our fallibilist point of view, it is obvious that if there is a multiplicity of conflicting scientific hypotheses around a certain question ('how does the heart functions?', 'how do the planets move?', etc.) then there ought to be a competitive pluralism. Each scientist should try to show 
that he has the most truthlike theory. To be a fallibilist is to have an epistemologically split vision on truth, and see that even if one as a researcher is wholeheartedly dedicated to the truth of one's own theory, one might in principle be wrong and some opponent right. If one is looking for truth but expects to find only truthlikeness, then there is no ground for claiming that one has monopoly on truth, and in general think that all one's opponents have not made real but merely perverted scientific inquiries. But since fallibilists aim at truth, a merely acceptive pluralism is of no use.

What does prototypical positivism and social constructivism, respectively, have to say about pluralism? True positivists aim at infallible knowledge. Now, if - but only if - a positivist thinks that he holds such a precious piece of knowledge, then there is for him no scientific reason (but perhaps personal) to be tolerant towards researchers with deviating views. In this sense, positivism contains in its theoretical kernel a view that can be used for defending a fundamentalist position in science; be then the actual positivists tolerant or not. True social constructivists, on the other hand, contain in their theoretical kernel a view that makes them tend heavily towards an acceptive pluralism. Since they do not believe in any notion of truth as correspondence between a theory (a social construction) and what the theory is about, competitions about truth and truthlikeness appear to them to be competitions around an illusion. They can, though, without contradicting their fundamental view, compete about who has made the most original or the most provocative construction.

In sum, we can write as follows about pluralism in scientific teaching and research:

- positivism might imply non-pluralism

- social constructivism naturally implies an acceptive pluralism

- fallibilism naturally implies a competitive pluralism

This being noted, we will in what follows stick to fallibilism and the form of pluralism it promotes: competitive pluralism. Our next question then is: does it make more than metaphorical sense to appoint winners and losers in scientific contests? How should they be chosen? For instance, does it make sense to try to solve truth-conflicts such as those listed below (when they are actual) by some kind of voting procedure among scientists? 
- Galen's theory of the functions of the heart and the blood versus the modern biomedical theory

- The miasma theory of diseases versus the contact theory

- The homeopathic theory versus the biomedical paradigm

- The meridian theory of acupuncture versus the biomedical paradigm

- Psychosomatic theories versus the biomedical paradigm

- Copernicus' theory of the solar system (with circular orbits) versus Kepler's (with elliptical orbits)

- The phlogiston theory of combustion versus the oxygen theory

- The special theory of relativity versus non-relativity theories

- The Darwinian theory of evolution versus the creationist theory

- The flat earth theory versus the sphere theory.

In one sense it is possible to take vote on truth and truthlikeness, but in another sense it is completely impossible. First some words about the impossibility. Truth and degrees of truthlikeness are relations between a hypothesis/paradigm and what the hypothesis/paradigm is presumed to be about (Chapter 3.5); and these relations exist or do not exist independently of how any group of scientists vote. This notwithstanding, it is of course just as possible to take vote on truth proposals as it is to take vote on political proposals. It is, for instance, possible to vote about whether evolutionary biology or Judaeo-Christian-Muslim creationism should be taught as a truth in schools and universities, but this voting does not settle the truth. If everyone votes the same, then there is complete consensus about correspondence between theory and reality; if people vote differently there is only a majority view about this correspondence. But in neither case does the vote infallibly guarantee the truth.

In the history of science, there have been few formal votes, but this fact does not speak against the views we have ventured. Even though the development of science has in fact taken place by an innumerable number of informal decisions about what shall be counted as truth, the same changes could have taken place by means of formal voting. The development of early science can very well be described as if scientists had now and then voted about competing hypotheses and paradigms. 
We have earlier (Chapter 3.5) pointed to the fact that applying the notion of truthlikeness to science allows one to think of scientific achievements the way engineers think of technological achievements. If a machine functions badly, engineers should try to improve it or invent a new and better machine; if a scientific theory has many theoretical problems and empirical anomalies, scientists should try to modify it or create a new and more truthlike theory. Now we want to add: it is possible to vote about what machine to use and what scientific theory to teach in schools, while waiting for better things to come in the future.

The kind of 'voting about truth' that we have now talked about has to be kept distinct from an epistemologically less problematic thing: 'voting about a classification schema when all the facts are agreed upon'. It might be said that on August 24, 2006, the General Assembly of the International Astronomical Union voted about whether our solar system contains nine or eight planets (is Pluto a planet or not?), that the '8-planets party' won, and that the 'Pluto-party' lost. But this is a very misleading description of what took place. What was really at stake was what classification schema for bodies orbiting the Sun that astronomers should use in the future. According to the schema that won, Pluto cannot be regarded as a planet, since it does not fulfill the third requirement in the new definition of a planet. A planet (1) orbits around the Sun, (2) because of its own mass it has an almost round shape, and (3) it has cleared the neighborhood around its orbit. Pluto is now classified as a 'dwarf planet'; there are also two further categories of objects orbiting the Sun: 'satellites' and 'small solar system bodies'. One kind of criticism waged at the new definition of 'planet' is that it will be very difficult to apply in other solar systems; this criticism might profitably be called methodology-pragmatic.

The voting had as its background new facts, the discovery of many very small bodies at the outskirts of our solar system. How should they be classified? Nonetheless, the voting in question was not due to any disagreement whatsoever about any facts about Pluto and the rest of the solar system. It was like a voting whether one should call people longer than $185 \mathrm{~cm}$ or longer than $190 \mathrm{~cm}$ 'tall', or whether one should measure lengths in yards or meters; and the history of science is replete with meetings where scientists have voted about what classification schemas 
and measuring units to use, even though they cannot be given such a dramatic (mis-)description as that concerned with Pluto.

In medicine, some classification schemas are debated and decided upon in the same purely methodology-pragmatic way as in the case of the schema for solar system bodies, but sometimes votings about classification schemas are inextricably mixed with votings about truths (what the facts of the matter are). They can even be mixed with votings about norms. The latter complication is due to the close connection between disease-disorder concepts and conceptions of normality and how things ought to be. Especially when it comes to classifications of mental diseases-disorders, it can be hard to tell whether the scientists that are voting do agree on all the facts or not, i.e., whether the different opinions are only due to different methodology-pragmatic views or whether different truth-beliefs and different norm-acceptances are at work as well.

A long story could for instance be told about how, over the years, the American Psychiatric Association (APA) has voted about homosexuality in relation to different versions of the Diagnostic and Statistical Manual of Mental Disorders (DSM); sometimes with gay activist groups demonstrating at APA meetings. Until the end of 1973, homosexuality was classified as 'sexual deviation', but then DSM-II was modified and homosexuality called 'sexual orientation disturbance'; it was now considered a mental disorder only if it was subjectively disturbing to the individual. DSM-III (1980) had at first a notion of 'ego-dystonic homosexuality', but in a revision (DSM-III-R, 1987) this notion was eliminated. The present DSM-IV-TR (2000) does not include homosexuality per se as a disorder, but it permits the diagnosis 'sexual disorder not otherwise specified' for persons who have a 'persistent and marked distress about sexual orientation'.

Having now made clear that it makes as much good sense to vote about truth proposals as it does to vote about political parties and their proposals, let us present three problems connected to the paradigm form of competitive pluralism: democracy. All three problems will then be shown to have a counterpart within the pluralism of science.

Where there is competitive pluralism there must be some formal or informal way by means of which it is decided who the winners and the losers are. At bottom, in all formally democratic elections the voters 
decide, but then there has to be (a) formal rules that tell who is to be allowed to vote; let us call this the maturity problem. Today, it is mostly seen as a matter merely of age, but during parts of the twentieth and the nineteenth centuries it was very much also a matter of profession (should unemployed and low-income people be allowed to vote?), sex (should women be allowed to vote?), and race (should black people be allowed to vote?). Apart from these kinds of rules, there also has to be (b) formal rules for how to transform all the votes to an appointment of winning parties or persons. In both cases, the rules can look different in different countries. In the (b)-case, we meet a special problem, the proportionality problem. Consider the following situation. There is a nation whose parliament has 100 members. From the very idea of representative democracy it might seem to follow that each political party that gets around one percent of the votes ought to have one member in the parliament. Why then do many countries have a lower limit (mostly between 3 and 6 percent), a fence, which says that parties that fall below this limit are not allowed to be represented in the parliament? The reason is that a democracy should not only meet the requirement of representing the wills of the voters, it has to meet the requirement of being a practically efficient decision procedure too. Democracy should be democracy in this world, not in an ideal supernatural world. And it is assumed that too many very small parties might often, with bad repercussions, block the parliamentary decision procedure.

A third problem well known in theories of democracy is called 'the paradox of democracy'. It is a special case of 'the paradox of freedom', which says that universal freedom cannot for logical reasons always be defended, since if everyone is free to do whatever he wants, everyone is free to enslave others, and then the latter are not free. That is, as soon as someone tries to enslave someone else, one has to constrain the freedom of the constrainer. The paradox of democracy says: all political parties cannot for logical reasons be given democratic rights in all logically possible situations, since if parties that want to overthrow the democracy will win a majority, they will abolish democracy. That is, as soon as a totalitarian party is on the brink of winning a parliamentary election, democrats are faced with the dilemma of either in an undemocratic way forbidding this 
party or in a democratic way let democracy come to an end. Absolute democracy is as much a myth as absolute freedom is.

We will next comment on 'the paradox of democracy', 'the proportionality problem', and 'the maturity problem' as they appear in science.

According to the view we have presented, defended, and think is implicitly adhered to by a majority of scientists, there are many kinds of reasoning and arguments in science that intertwine in the final decisions. Empirical sciences can often use some deductive inferences, but they have in the main to rely on much weaker forms of argumentation patterns. In particular, they have somewhere to bring in argumentation from perceptions. This means that at least empirical science cannot regard any holy book as completely authoritative. What totalitarian parties are to democracy, holy-book-scientists are to science. As the former are antidemocratic, the latter are anti-scientific. The paradox of scientific pluralism can be stated thus:

- For logical reasons, all kinds of scientists cannot be allowed a place in science in all logically possible situations, since if scientists who want to make a certain book overthrow the reliance on systematic observations will take the lead, they will abolish empirical science; in other words: absolute scientific pluralism is a myth.

We can imagine that a majority of voters vote for a party promoting the abolishment of democracy. But what would the corresponding thing look like in science? Well, one way it could take place is that a group of holybook-scientists manage by ordinary scientific argumentation to convince a majority of ordinary scientists that a holy book of some sort contains all interesting truths. If such an incredible development would one day become reality, then ordinary scientist would face with the dilemma of either in an unscientific non-argumentative way force some scientists to leave the scientific community or let science become heavily restricted.

Usually, people in the creationist movement and in the flat earth movement are today regarded as the two most conspicuous cases of people who simply do not take science seriously. But there is an interesting difference between them. Most creationists can be said to rely completely 
and only on a literal reading of the Bible, and these are the ones we are highlighting now, but the majority of the members of the flat earth movement have so far had no similar epistemological views; even if they nonetheless may look crazy. (It should be added and noted that some creationists have a view that was quite common among medieval theologians: truths about nature revealed by the Bible can be shown to be true also by means of man's natural reason. Such creationists try intensely to find anomalies in evolutionary biology; and if such anomalies there are, they ought of course to be seriously discussed.)

In many cultures long ago, Earth was taken to be as flat as it appears in most everyday perceptions, but already the thinkers of ancient Greece found out that this seems not to be the case. The latter noticed that the star constellations were different in Greece and Egypt, and that the shadow of the Earth on the moon at lunar eclipses indicates that Earth is a sphere. If Earth is a sphere, then some of our everyday observations must be illusory; e.g., water surfaces must be bent but look flat. On the other hand, if the flat earthers are right, then some other perceptual observations, such as the shape of the line that separates the dark and bright part of the moon, have to be given quite complicated explanations.

The modern flat-earth movement was launched in England with the publication in 1849 of a sixteen page pamphlet, Zetetic Astronomy: A Description of Several Experiments which Prove that the Surface of the Sea Is a Perfect Plane and that the Earth Is Not a Globe! Its author, Samuel Birley Rowbotham (1816-1884), repeatedly emphasized the importance of sticking to the facts. He called his system 'zetetic astronomy', because he sought only facts; 'zetetic' comes from the Greek verb zetetikos, which means to seek or inquire. He wrote: "Let the practise of theorising be abandoned as one oppressive to the reasoning powers, fatal to the full development of truth, and, in every sense, inimical to the solid progress of sound philosophy." Later, in a very empirically minded book, Earth Not a Globe (1881), Rowbotham claimed to have shown in a number of measurements that there is no curvature in the water of big lakes. The modern International Flat Earth Society was created in the 1950s, in the 1990s it had around 3000 members, but since then it has declined. The truly hard times for its members arose when the satellite pictures of the Earth were publicized. But the flat earthers did not say that their view is 
beyond empirical control. Instead, they argued that all these photographs, as well as the whole trip to the moon in 1970, were mere movie fakes.

Whereas the holy-book-scientists of the creationist movement can be used to illustrate the paradox of scientific pluralism, the flat earth movement can illustrate the proportionality problem of scientific pluralism; not every idea that argues in a formally scientific way need to be allowed a place in science. However, we will not here try to find any default rules for where such fences for empirical theories ought to be installed. The third problem mentioned, the maturity problem, i.e., who is to be reckoned a full citizen in a scientific community, seems at first not be a hard problem. A default rule could be that at least all doctoral students and all more qualified persons should be such citizens. But then one forgets that they ought also to have reflected a little on fallibilism and the need for pluralism in science. Otherwise, they may be just as dogmatic as holy-book-scientists and scientists who think they have found an infallible truth can be; or they may be just as acceptive as social constructivists allow their adherents to be.

We would now once more like to highlight what we have labeled 'type $\mathrm{T}$ error' (Chapter 6.4). The type T error is the mistake to neglect a significant correlation and a useful treatment because its first protagonists claimed the data in question are caused by a causal mechanism that science cannot validate. Its importance for pluralism can be seen by the fact that many Western physicians by committing this type of error vis-à-vis acupuncture (in the 1950s and 60s) made the acceptance of this therapy unnecessary hard. According to our analysis, they should have interpreted the implausible meridian mechanism away, and then looked at the remaining pure correlation hypothesis. A mechanism theory can be looked upon in two ways, either in its entirety with its mechanism or without the mechanism. This makes it possible, as we will show, to widen the pluralism in the medical sciences. Look at the matrix in Table 1 (of course, both the dimension 'high-low statistical effect' and the dimension 'plausible-implausible mechanism' take degrees, even though these degrees are abstracted away: 
The statistical effect of the treatment is:

High Low

$\begin{array}{lll}\text { The underlying mechanism is plausible: } & 1 & 2 \\ \text { No underlying mechanism is proposed: } & 3 & 4 \\ \text { The underlying mechanism is implausible: } & 5 & 6\end{array}$

Table1: Six different kinds of epistemological situations for a hypothesis.

Assume that we are medical scientists who, based on reflections around causal mechanisms that are well established in the medical-scientific community, have proposed a new kind of treatment; that we have tested it according to normal methodological standards; and that we have a high statistical effect. That is, we sit at the moment quite safely somewhere in box 1 in the matrix. From this perspective, the question then is: how tolerant ought we to be towards colleagues who at the moment are in the other boxes? Let us add that these colleagues are firmly convinced that sooner or later in the development of science they will enter box 1 too.

The mentioned proportionality principle seems to make it reasonable for us to create toleration fences somewhere on the various possible roads down to box 6. Let us for a moment forget that the dimensions in the matrix take degrees and assume that, in fact, there are only extremely high and low correlations and only extremely plausible and implausible mechanisms. The proportionality principle would then, reasonably, allow us to forbid all theories in the second column (boxes 2, 4, and 6), and seemingly also box 5, but what about the hypotheses in box 3? Answer: they should be allowed, since the statistical effect is high and they are not connected to any obscure mechanisms. But this acceptance has an interesting further consequence in relation to box 5 . Since we can take a theory from box 5 and abstract away the presumed mechanism, i.e., turn the mechanism theory into a black-box theory, we can so to speak move a theory from box 5 to box 3. But this seems to imply that we ought also to be somewhat tolerant towards people working with theories in box 5. After all, it was probably their mechanism thinking that made them hit upon what we happen to regard as a good black-box theory. 
We will end this subchapter with still another analogy between voting in the political sphere and voting in science. Assume that there is a nation where the two largest parties, $\mathrm{P}$ and $\mathrm{Q}$, both present themselves as creating, in the long run, the best possible life for all the citizens. In the short run, however, from a social-economical point of view, the P-party explicitly favors stratum A and disfavors stratum B, whereas the Q-party takes it the other way round. From a common sense psychological point of view, one might then claim that it is easier for citizens in stratum A than for citizens in stratum B to reach the conclusion that the P-party is the best party for the whole nation; and vice versa for people in stratum B. But to make the whole picture clear, two more things should be noted. First, the sociopsychological fact noted states only that there is such a tendency; it does not mean that each and every member of stratum A is pre-determined to vote for the P-party. Second, the future may well tell (or at least indicate) whether or not the party who gets the power makes life better for all citizens or only for people in stratum A. This way of looking at political elections can be transferred to science.

Assume that in a scientific discipline two paradigms, $\mathrm{P}$ and $\mathrm{Q}$, are competing about what paradigm is the most truthlike one. Paradigm $\mathrm{P}$ has been constructed by research groups in the so-called 'A-universities' and Q in the 'B-universities'. Doctoral students at the A-universities will then have a tendency to think that the P-paradigm is more truthlike than the Qparadigm; and vice versa for the doctoral students at the B-universities. But the doctoral students are not pre-determined to support the majority view at their home university. Furthermore, the future may well contain observations that make almost everyone think that one of the paradigms is much more truthlike than the other one. Let us repeat a sentence from Chapter 3.5: Fallibilism makes it possible to adhere simultaneously to the views that (i) science aims at truths, (ii) captures partial truths, and (iii) accepts theories partly because of the way these conform to dominant views in the surrounding society.

\subsection{Methodological pluralism}

What comes first, the hen or the egg? Similarly, one may ask: what comes first, the object of study (theory) or the methodology? Even if in the latter case, for sure, the two might in principle come simultaneously, there is a 
kind of asymmetry in favor of theory. Think of the difference between molecular biology and studies in comparative literature. In molecular biology one can and has to do experiments with matter, and it makes good explanatory sense to try to find smaller units than molecules. In comparative literature, on the other hand, it is completely senseless to make laboratory experiments, and if one looks at too small pieces of texts the overarching meanings of the texts that should be compared are lost. Here, the choice of object of study comes before the choice of methodology. However, on a more concrete level where one works with very specific hypotheses against the background of an already chosen general theory, the concrete methodological rules might be said to come first. These two levels have to be kept apart if the theory-methodology interplay in science shall not be turned into a low-traffic one-way street.

As stated in Chapter 2.4, Kuhn first distinguishes between two parts of a paradigm, (i) a disciplinary matrix and (ii) exemplars/prototypes, and then between three components of the matrix: (ia) metaphysical assumptions, (ib) symbolic generalizations, and (ic) values. The values might equally well be called 'general methodological norms'. Our comment in the last paragraph means that we regard the metaphysical assumptions and the symbolic generalizations as being logically prior in relation to the general methodological norms. And this is quite in conformance with Kuhn's views. He thinks that even the basic empirical sciences have to contain assumptions that are not directly based on their experiments and observations, i.e., the methodologies of experiments and empirical data gathering are only possible provided some presuppositions. Applied to the clinical medical paradigm (as expounded in Chapter 6), these views imply that the methodology of the randomized controlled trial has to be regarded as being subordinated to the epiphenomenalist materialist ontology of the biomedical paradigm.

This fact, in turn, means that paradigm conflicts between, for instance, the biomedical paradigm and those of alternative medicine cannot be solved by a simple recourse to methodology. To the same extent that pluralism in science should reckon with pluralism between paradigms, it has to reckon with methodological pluralism too.

It is often said that science requires a certain critical mass of researchers in order to achieve anything of real interest. Therefore, it may be a good 
thing to monopolize a methodology. If many researchers are working with the same methodology, the chances of getting skilled and methodologically creative researchers increase, and this is needed in order to show what the basic theory really is able to accomplish. If the researchers must learn many different methods, they may not learn all of them properly. But, on the other hand, it is equally true that such a monopoly might hamper the growth of knowledge. What to do? Answer: competitive pluralism.

A long standing topic in the philosophy of science has been the opposition between quantitative and qualitative methods. It dates back to the rise of modern science, which is the rise of mathematical physics. Galilei, one of its true heroes, claimed straightforwardly: the book of nature is written in the language of mathematics. He distinguished strictly between the primary qualities, which are properties of the material things in nature, and secondary qualities, which are properties belonging to entities in the mind such as (perceived) colors, sounds, smells, pleasures, and pains. The former, he claimed, are the object of physics, and the latter cannot be systematically studied. In the same era, great philosophers such as John Locke and Descartes made similar ontological bipartitions. During the second half of the twentieth century, this dichotomy was turned into a distinction between working with hard data and soft data, respectively.

In this latter debate, the notion of hard data fused the ontological feature of being able to be represented by means of numbers with the epistemological property of providing pretty secure knowledge, and the notion of soft data fused the feature of not being able to be quantified with the epistemological property of providing only subjective interpretations. When the ontological and the epistemological aspects are kept distinct, however, the remarks below can be made. They end with the conclusion that the opposition and perceived difference between the two methods have been considerably exaggerated.

First epistemology; from the fallibilistic perspective of this book no gap or clear-cut distinction between secure knowledge and subjective interpretations can be found. All empirical data include some kind of interpretation. This fact lessens in itself the importance of the epistemological part of the debate. But even more, nothing in principle says that quantitative measurements are always more certain than what one can obtain from, say, interviewing people. 
Our second and ontological remark says: every empirical science has to be concerned with some qualitative features. Pure numbers exist only in mathematics; quantities have to be kept distinct from mathematical numbers. Let us explain.

Quantitative expressions such as 'a mass of 4 kg', 'a length of 9 m', 'a temperature of $37^{\circ} \mathrm{C}$ ' consist of three easily distinguishable linguistic parts:

1. a name of a physical dimension ('mass', 'length', and 'temperature', respectively)

2. a so-called numeral (4, 9, and 37 , respectively); only in abstraction from the rest of the quantitative expression does the numeral refer to a mathematical number

3. a name of a conventionally chosen standard unit (' $\mathrm{kg}$ ', ' $\mathrm{m}$ ', and ' ${ }^{\circ} \mathrm{C}$ ', respectively); this unit cannot be chosen until the determinate properties of the physical dimension in question has already been ordered the way numbers are ordered on the number line.

Much can and has been explored about formal and other features of scales and quantities, but we will not go into such details in this book. Here we only want to point to the fact that each basic physical dimension is a purely qualitative feature that exists independently of whether or not it becomes quantified. That is, the quantities $4 \mathrm{~kg}, 9 \mathrm{~m}$, and $37{ }^{\circ} \mathrm{C}$ are quantifications of the qualitative physical dimensions mass, length, and temperature, respectively. The ordinary opposition between 'qualities' and 'quantities' is at bottom an opposition between 'qualities that cannot be quantified' and 'qualities that can be turned into quantities'. In everyday language, expressions often become condensed. Regardless of whether or not pain research will succeed in quantifying pain, pain will still remain a quality. If pain researchers succeed, it will enable us to rank and more easily compare different pains.

For some unclear reasons, philosophers of science have now and then written as if talk about physical dimensions would become linguistically superfluous as soon as the determinate quantities with the standard unit have entered language. But this cannot be true, since if we want to make 
everything philosophically explicit we need to state trivial 'laws' such as these:

- no object can possibly at one and the same time take two values of the same physical dimension; e.g., no object can have a mass of both $4 \mathrm{~kg}$ and $2 \mathrm{~kg}$

- only quantities of the same physical dimension can be added together and give rise to a meaningful sum; e.g., ' $4 \mathrm{~kg}+9 \mathrm{~m}$ ' has no meaningful sum.

A good case can even be made against Galilei's dictum that nature is written in the language of mathematics. Shape is just as much a basic property of material things as size and mass are, but so far no one has managed to construct for all determinate shapes something resembling even remotely the quantifications of size and mass. The physical dimension of shape contains not only good-behaving geometrical shapes, but each and every kind of curious and crazy-looking determinate shape there is; two-dimensional as well as three-dimensional.

In principle, it could have been the case that even though shape is a basic property of material things it is not important in science. However, this is not at all so. Two rhetorical questions ought to be enough to make this fact clear: (i) 'what would anatomy be without shape talk?' and (ii) 'what would molecular biology be without shape talk?' The discovery of the DNA molecule is partly a discovery of its shape.

The basic difference between so-called quantitative and qualitative methods can now be spelled out as follows: when we deal with quantitative methods, the qualities are taken for granted and we look for and focus on the quantitative aspect; when we apply pure qualitative methods, we are either not interested in quantitative aspects or the qualities are not amenable to quantitification. It should also be mentioned that the natural sciences might involve qualitative methods, and the humanities quantitative, even though the natural sciences are dominated by quantitative methods and the humanities by qualitative. If we may refer back to our case study of Harvey's scientific practice (Chapter 4.8), it now illustrates our point that research can contain both qualitative and quantitative elements. 
When quantification is possible, however, it makes comparisons in the domain at hand extremely easy and efficient. When you state that something has 'a mass of $4 \mathrm{~kg}$ ', 'a length of $9 \mathrm{~m}$ ', 'a temperature of $37^{\circ} \mathrm{C}$ ' you obtain in each case an infinite number of comparisons for free. A similar advantage has systematic classifications and taxonomies, even though they give rise only to a finite number of comparisons. To these topics we will return in Chapter 11.

\subsection{Pluralism from the patient's perspective}

This little subchapter is inserted only to forestall the possible misunderstanding that patients naturally should have the same view on medical pluralism as the medical scientists and clinicians have. Let us take a quick look at the different perspectives.

The medico-scientific community needs some competitive pluralism in order to efficiently produce good diagnostic tools, treatments, and preventive measures. In each case the result is something that should be applicable to a whole population of some kind, i.e., the populations that have disease $\mathrm{A}$, that have a risk of getting disease $\mathrm{A}$, that have disease $\mathrm{B}$, that have a risk of getting disease $B$, etc. As tax payers financing medical research, patients have the same interest in pluralism as the medical community has, but what about the patients as patients?

When one is sick, one primarily wants to become healthy. One is not especially interested in the whole population that happens to have the same disease. Existentialists used to say things such as 'my death is mine' and 'my life is mine', stressing that an individual can never be regarded as only and completely part of some community or other. In the same vein it is true for patients to say: 'my disease is mine' and 'my possible curing is mine'. What follows from this observation? On an abstract level, mainly two things:

(a) black box theories count as much as mechanism theories

(b) lottery thinking ('I may win even though the probability is very low') can be rational

(a) From an existentialist point of view, the mechanisms (pathogenesis and etiology) behind the disease and its curing are of no special interest. If 
something has cured me as an individual, then afterwards I am happy. I don't care much whether it is due to a well known biomedical mechanism, to a completely unknown mechanism, to a placebo effect, or even to an effect (e.g., homeopathic) that the medical community finds unbelievable.

(b) Much has been investigated about how to be rational in lotteries and situations in life that have a similar stochastic structure. To put one conclusion simply, it seems impossible to say that a certain behavior is rational in itself. To some extent it always depends on whether you are an extremely cautious person or a person who is fond of taking risks; and then there are all the in-betweens. Therefore, it is impossible to say that a patient who spends much money on a treatment that has a low statistical effect is irrational; especially if the gains are high, i.e., that the disease is very serious.

The last remark notwithstanding, there is in both case (a) and case (b) a kind of rationality at work, but one that is mostly adhered to by the patients themselves. It seems rational to start with treatments that have high statistical effects based on plausible mechanisms (slot 1 in Figure 1), but the interesting thing is what happens if such treatments fail. There are then, it seems, very good reasons to try black box theories, and if even these fail one may well opt for implausible theories. That is, we obtain the slots order 1, 3, and 5 in Figure 1. However, having accepted to play the medical lottery game, one may continue with the slots down the second column, i.e., 2, 4, and 6. It is in all probability often this kind of reasoning, rather than reasoning about the nature of medical science that makes it attractive for patients to consult quacks.

\section{Reference list}

Bunge M. Phenomenological Theories. In Bunge (ed.) The Critical Approach to

Science and Philosophy. Free Press of Glencoe. New York 1964.

Johansson I. Pluralism and Rationality in the Social Sciences. Philosophy of the Social

Sciences 1991; 21: 427-443.

Kvale S. To validate is to question. In Kvale S. Issues of Validity in Qualitative

Research. Studentlitteratur. Lund 1989.

Lynoe N, Svensson T. Doctors' attitudes towards empirical data - a comparative study.

Scandinavian Journal of Social Medicine 1997; 25: 210-216. 
Mitchell S D. Biological Complexity and Integrative Pluralism. Cambridge University Press. Cambridge 2003.

Wulff H, Pedersen SA, Rosenberg R. Philosophy of Medicine - an Introduction. Blackwell Scientific Press. Cambridge 1990. 